\title{
Removal of Cr (VI) Using Low Cost Activated Carbon Developed By Agricultural Waste
}

\author{
${ }^{1}$ Ravi Kumar, ${ }^{2}$ Dinesh Kumar Arya and, ${ }^{3}$ Nouratan Singh, ${ }^{4}$ Hirdayesh Kumar \\ Vats \\ ${ }^{1,4}$ Department of Chemistry, OPJS University, Churu, Rajasthan, India. \\ ${ }^{2}$ Acharya Narendra Dev College Govind Puri, Kalkaji New Delhi-110019 \\ ${ }^{3}$ Scientific and Applied Research Center [SARC], Meerut, Uttar Pradesh, India.
}

\begin{abstract}
Rice straw is find out as agricultural waste material labundantly in india. It is also used in paper industry due to it abundantly available in rice-producing countries. Activated carbon of rice straw (ACRS) was used to remove $\mathrm{Cr}(\mathrm{VI})$ from waste water. The Batch process were used to evaluate the effect activated carbon of rice straw for $\mathrm{Cr}(\mathrm{VI})$ removal from aqueous solutions. The adsorption studies on $p H$ effect, contact time, adsorbent dose were examined. The removal decreased from 74.2 to $47.2 \%$ by increasing the $\mathrm{Cr}$ (VI) concentration from 1.5 to $5.0 \mathrm{mg} / \mathrm{l}$. Removal, however, decreased from 80.3 to $7.2 \%$ by increasing the adsorbent particle size from $100 \mu \mathrm{m}$ to $200 \mu \mathrm{m}$. The adsorbed dose of $\mathrm{Cr}$ (VI) tend to increase with the increase of $\mathrm{pH}$. It has been found that a low cost and high capabilities of the ACRS make it potentially attractive adsorbent for the removal of $\mathrm{Cr}$ (VI) from wastewater.
\end{abstract}

Keywords: Removal; rice straw ; adsorption ; pH; water; Activated carbon etc.

\section{Introduction}

Chromium is an significant heavy metal widely used in leather industry, electroplating, metal processing and paint and pigment. Removal of heavy metals by adsorption is an crop up field of research ${ }^{[5]}$, Activated carbon is an effective adsorbent for the treatment of wastewater rich in metals like $\mathrm{Cr}, \mathrm{Ni}, \mathrm{Cu}^{[9]}$. It can completely removes the heavy metal from the dilute solutions. It has been found that Commercial activated carbons are very expensive. So our researchers are working on low cost new adsorbents, and studied by researchers which are suitable for water pollution control ${ }^{[2,3]}$. Agricultural waste are readily available and low in cost also. It has been studied by previous research on removal of heavy metal with the help of agricultural waste adsorbent like sugarcane bagasse ${ }^{[6]}$, plant waste leaves ${ }^{[7]}$, pomegranate peel ${ }^{[4]}$, rice hull ${ }^{[10]}$, saw dust ${ }^{[1]}$ cotton seed and tea leaves ${ }^{[9]}$ etc. it has been studied that Peat moss effective in adsorbing heavy metals. Coconut shell, husk ash and biomass also gave good results. This work reported here deals with the adsorption studies on the activated carbon prepared from rice straw for the removal of chromium (VI) from aqueous solutions. The effect of various parameters such as adsorbent dosage, initial metal concentration and $\mathrm{pH}$ has been studied.

\section{Material And Method}

The rice straw is an agricultural waste in india. Rice straw was washed with water and subsequently dried at $105^{\circ} \mathrm{C}$ for $24 \mathrm{~h}$ to remove moisture content. The dried RS was ground and sieved to a particle size of 1-2 $\mathrm{mm}$ before loading it in a muffle furnance. The temperature and time were optimized by observing the surface properties of the activated products obtained. The $100 \mathrm{~g}$ of dried samples were carbonized at 450 and $700{ }^{\circ} \mathrm{C}$ for $2 \mathrm{hr}$ in a muffle furnace. After that charcoal was crushed and sieved to a size smaller than $850 \mu \mathrm{m}$ to obtain the activated carbon of rice straw (ACRS) The sample was washed with hot deionized water and hydrochloric acid $(0.1 \mathrm{M})$ until the $\mathrm{pH}$ reached 6.5-7. After this products were sieved to the desired particle sizes such as $30-200$, 200 - 250, and $250-300$ mesh. The activated carbon of rice straw (ACRS) having the $30-200$ mesh size was used in adsorption study. Lastly the product was stored in a vacuum desiccators until required. The developed carbons are designated as ACRS (activated carbon of rice straw).

\section{Batch Adsorption Experiments}

Batch adsorption experiments were carried out by agitating $1.0 \mathrm{~g}$ of rice straw activated carbon sample with $50 \mathrm{ml}$ aqueous solution of $\mathrm{Cr}$ (VI) of desired concentration, temperature and $\mathrm{pH}$. It has been take in separately cleaned polythene bottles on a shaking thermostat with a constant speed of $1000 \mathrm{rpm}$. At the end of predetermined time intervals, activated carbon of rice straw (ACRS) was removed from the aqueous solutions by centrifugation at $10,000 \mathrm{rpm}$ for $20 \mathrm{~min}$. The progress of adsorption was assessed by evaluating by the residual concentration of $\mathrm{Cr}(\mathrm{VI})$ by an atomic adsorption spectrophotometer [15]. 


\section{Preparation of Synthetic Chromium Cr(VI) Waste Water}

Aqueous solution $1000 \mathrm{mg} / \mathrm{l}$ of chromium $\mathrm{Cr}(\mathrm{VI})$ was prepared by dissolving in $\mathrm{K}_{2} \mathrm{Cr}_{2} \mathrm{O}$ 7 (s) in distilled water and diluted to get desired concentration 1.5 to $5 \mathrm{mg} / \mathrm{l}$. the chromium concentration was measured by (AAS) atomic adsorption spectrophotometer.

\section{Effect of pH}

Experiments were carried out at different $\mathrm{pH}(2,3,4,5,6,7$ 8) and the initial $\mathrm{Cr}(\mathrm{VI})$ concentration of $1.5 \mathrm{mg} / \mathrm{L}$ at $25{ }^{\circ} \mathrm{C}$. The results of the effect of $\mathrm{pH}$ on adsorption of $\mathrm{Cr}(\mathrm{VI})$ are presented in Fig. 2 reveals the adsorption capacity of metal ions. At $\mathrm{pH} 8$, and $1 \mathrm{~g}$ of ACRS was able to give chromium removal efficiency of $96.72 \%$. It was studied that the total amount of adsorption of $\mathrm{Cr}$ (VI) onto ACRS $42 \%$ to $90 \%$ with an increase of $\mathrm{pH}$ from 3.1 to 8.0. it has been found that $\mathrm{pH}$ value of the aqueous solution influences on the adsorption of $\mathrm{Cr}(\mathrm{VI})$ at the solid-liquid interfaces. The activated carbon has a negative surface charge in solution. Due to change of PH of solution charge changes, and the sorption of charged species is affected (attract ion between the positively charged metal ion and the negatively charged ACRS surface. it is expected that ACRS surface became more negatively charged. As well as $\mathrm{pH}$ value increase the electrostatic attraction forces enhanced cationic metal ions adsorption it has been reported for $\mathrm{Ni}(\mathrm{II})$ and $\mathrm{Cd}(\mathrm{II})$ adsorption onto bagasse fly $\operatorname{ash}^{[14]}$.

it is clear that Maximum 90 percent removal of $\mathrm{Cr}(\mathrm{VI})$ by the adsorption at $\mathrm{pH}$ 8.0.

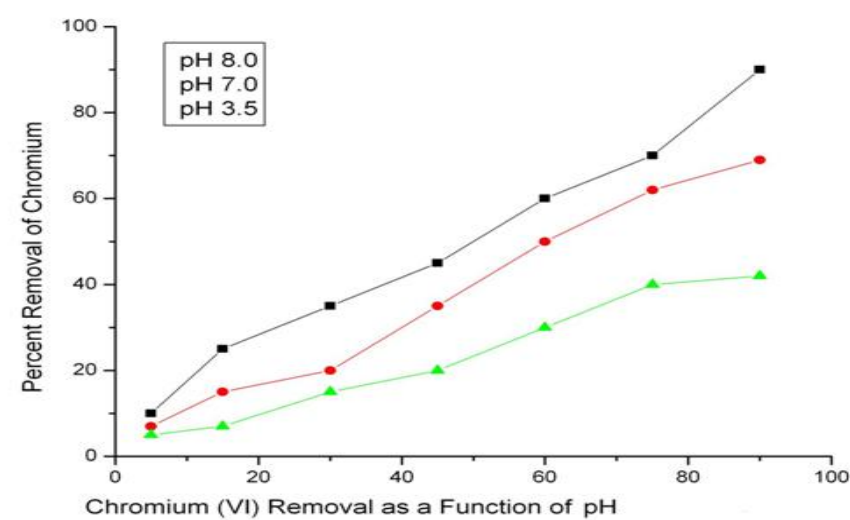

FIG 1.0 The Effect of Contact Time and $\mathrm{pH}$ value for the Removal of $\mathrm{Cr}(\mathrm{VI})$

\section{Effect of Contact Time and initial Concentration}

Researcher has been studied that how affect contact time and concentration on removal of heavy metal. The Effect of contact time and concentration on the removal of $\mathrm{Cr}(\mathrm{VI})$ has been verified in Fig.1.It is reveal from this figure that by varying concentration of $\mathrm{Cr}(\mathrm{VI})$ in solution from 1.5 to $5.0 \mathrm{mg} \mathrm{l^{-1 }}$, the adsorption efficiency decreased from 76 to $46 \%$.. This figure reveals sharp rise in removal of $\operatorname{Cr}(\mathrm{VI})$ in initial stages. Then gradually it attains equilibrium in $100 \mathrm{~min}$ and becomes constant. It shows that the process of $\mathrm{Cr}(\mathrm{VI})$ removal on ACRS is highly concentration dependent. Higher percentage removal in lower concentration ranges has lot of industrial significance as in most cases the waste waters and industrial effluents have been recited to have lower concentrations of metallic species including that of $\mathrm{Cr}\left(\mathrm{VI}{ }^{[12]}\right.$

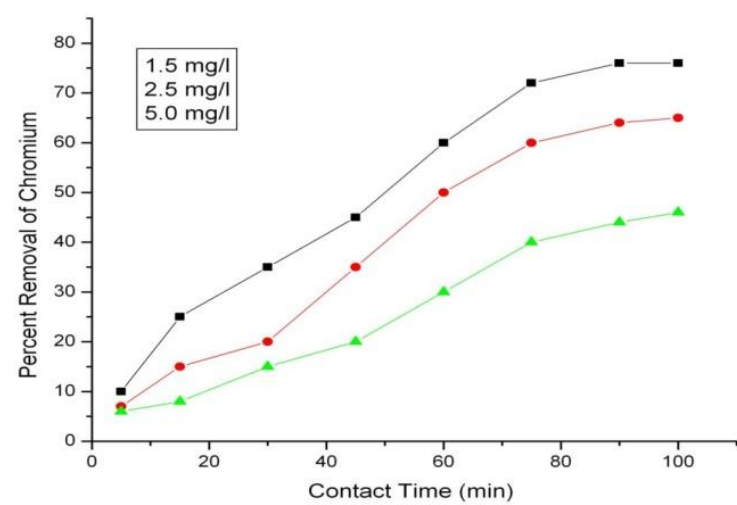

FIG 2.0 The Effect of contact time and concentration on the removal of $\mathrm{Cr}(\mathrm{VI})$ 


\section{Effect of Particle Size}

In this research we take variation in particle size and study the effect of adsorbent particle size on removal of $\mathrm{Cr}(\mathrm{VI})$, experiments were conducted at 100,150 and $200 \mu \mathrm{m}$ diameter of Activated carbon of rice straw(ACRS) particles. It has been found that the removal of heavy metal decrease from 79.2 to $53.3 \%$ by increasing the diameter of the adsorbent particles from $100 \mu \mathrm{m}$ to $200 \mu \mathrm{m}$ at $1.5 \mathrm{mg} \mathrm{l}^{-1} \mathrm{Cr}(\mathrm{VI})$ concentration, $\mathrm{pH}$ 8.0 and $298 \mathrm{~K}$ in (Fig.3). It is revealed that at Higher external surface area in smaller particle sizes at a constant amount of the adsorbent is the reason for higher removal of chromium at low particle sizes ${ }^{[12,13]}$. It is clear that the increase in metal removal with particle size does not have a 'directly proportional' relationship. It has been found that the lower free concentration of $\mathrm{Cr}(\mathrm{VI})$ for smaller Activated carbon of rice straw (ACRS) particles is significantly less than that for the larger adsorbent particles. This leads to comparatively lower value of adsorbed species.

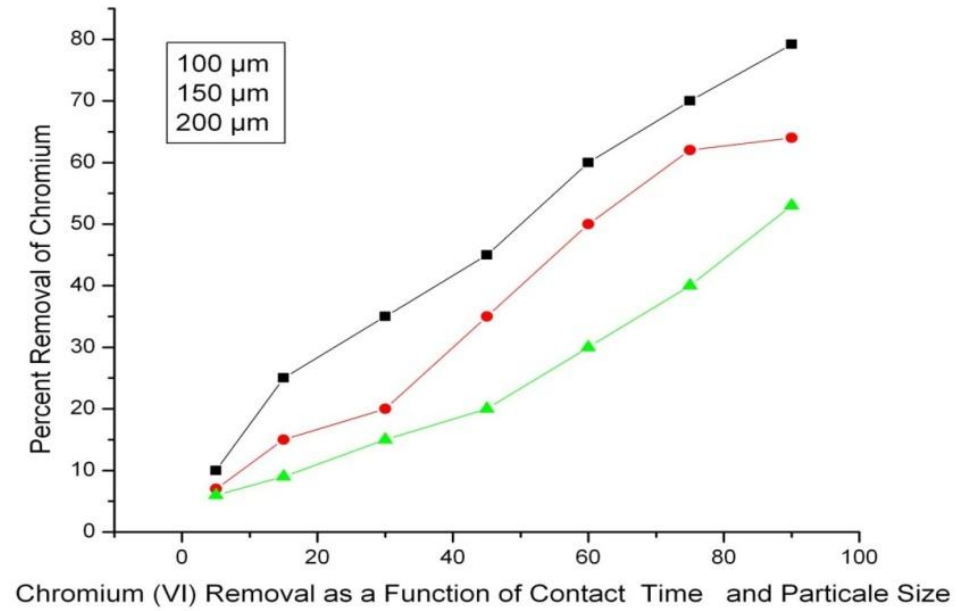

FIG 3.0 The Effect of contact time and particle size on the removal of $\mathrm{Cr}(\mathrm{VI})$

\section{Effect of Adsorbent Dose}

The effect of adsorbent doses of Rice straw activated carbon ranging 2-9 g/L and chromium removal are shown in Fig.4. The results indicate that the percentage removal of chromium metal ions increases as the adsorbent dose increases by giving removal efficiency from $45.0 \%$ to $97.12 \%$ for rice straw activated carbon. The removal efficiency and specific uptake of metals depend on type and quantity of the biosorbent. The increase in percentage removal of chromium with increase in adsorbent dose was due to the availability of more and more adsorbent surfaces for the solutes to adsorb.

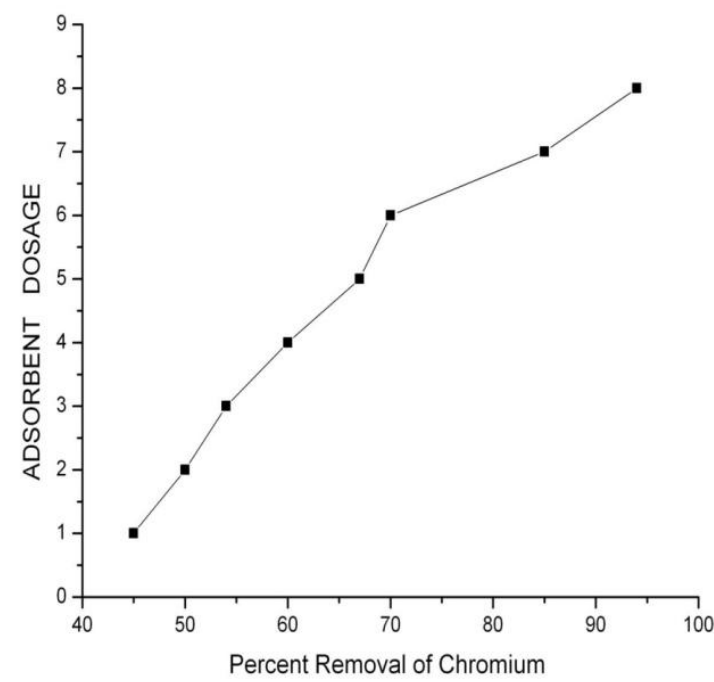

FIG 4.0 The Effect of adsorbent dose on the removal of $\mathrm{Cr}(\mathrm{VI})$ 


\section{Conclusions}

It has been found that the Activated carbon of rice straw(ACRS) to be a very effective adsorbent for the efficient removal of $\mathrm{Cr}(\mathrm{VI})$ from water. The adsorption capacity of the Activated carbon of rice straw(ACRS) was maximum $63.5 \mathrm{mg} \mathrm{Cr}(\mathrm{VI})$ absorb at temperature of $30{ }^{\circ} \mathrm{C}$ and at the initial $\mathrm{Cr}(\mathrm{VI})$ concentration of $400 \mathrm{mg} / \mathrm{L}$ and $\mathrm{pH}$ 7.0. The adsorbed amounts of $\mathrm{Cr}$ (VI) tend to increase with the increase of $\mathrm{pH}$ value. The relatively low cost and high capabilities of the Activated carbon of rice straw (ACRS) make it potentially attractive adsorbent for the removal of $\mathrm{Cr}(\mathrm{VI})$ from waste water. it has been studied that Activated carbon of rice Straw(ACRS) used as a good adsorbent for $\mathrm{Cr}(\mathrm{VI})$ removal. The removal is highly dependent on initial concentration of $\mathrm{Cr}(\mathrm{VI})$ in solution and higher removal $76(\%)$ has been observed in lower concentration ranges. This study highlights that the rice straw carbon can be used as a low cost adsorbent for removal of heavy metal from waste waters. Researcher found that rice straw activated carbon has great capacity for adsorption and is highly efficient. The percentage removal of chromium was high with increasing of contact time and the equilibrium time is nearly 3 hours. It has been found that the removal of heavy metal decrease from 79.2 to $53.3 \%$ by increasing the diameter of the adsorbent particles from $100 \mu \mathrm{m}$ to $200 \mu \mathrm{m}$ at 1.5 $\mathrm{mg} \mathrm{l}^{-1} \mathrm{Cr}(\mathrm{VI})$ concentration. The percent removal of heavy metal also increases with increased adsorbent dose as evident from the experiments that an adsorbent dose of $9 \mathrm{~g} / \mathrm{L}$ completely $97.12 \%$ removes the chromium. As the rice straw is easily available and is also cost effective so it can be used as an good adsorbent for complete removal of $\mathrm{Cr}(\mathrm{VI})$

\section{References}

[1]. Bulut, Y. and Tez, Z. (2007). Removal of heavy metals from aqueous solution by sawdust adsorption. J. Environ. Sci. (China), 19(2), 160-6.

[2]. Dakiky, M., Khamis, M., Manassra, A. and Mereb M (2002). Selective adsorption of chromium (VI) in industrial wastewater using low-cost abundantly available adsorbents. Adv. Environ. Res., 6 (14), 533-543.

[3]. Demirkas, E., Kobya, M., Senturk, E. and Ozkar, T. (2004).Adsorption kinetics for the removal of chromium (VI) from aqueous solutions on the activated carbons prepared from agricultural wastes. Water SA., 30 (4), 533 - 539.

[4]. El-Ashtoukhy, E. S. Z., Amin, N. K. and Abdelwahab, O. (2008). Removal of lead (II) and copper (II) from aqueous solution using pomegranate peel as a new adsorbent.Desalination, 223, 162-173. 923

[5]. Gupta, S. and Babu, B. V. (2006). Adsorption of Cr(VI) by a low cost adsorbent prepared from Neem Leaves. Proceedings of National Conference on Environmental Concentration, BITS Pilani, 1-3, 175 -180.

[6]. Homagaia, P. L., Ghimirea, K. N. and Inoueb, K. (2010). Adsorption behavior of heavy metals onto chemically modified sugarcane bagasse. Bioresource Technology 101 (6), 2067-2069.

[7]. Horsfall, M. and Vicente, J. L. (2007). Kinetic study of liquid phase adsorptive removal of heavy metal ions by almond tree (Terminalia Catappa L.) leaves wastes. Bull. Chem. Soc. Ethiop., 21 (3), 349-362.

[8]. Iqbal, M., A Saeed and Akhtar, N. (2002). Petiolar felt sheeth of palm: a new biosorbent for the removal of heavy metals from contaminated water. Bioresource Technology, 81, 151- 153.

[9]. Lavecchia, R., Pugliese, A. and Zuoroo, A. (2010). Removal of lead from aqueous solutions by spent tea leaves. Chemical Engg. Transactions, 19, 73-78.

[10]. Lin,C. I. and Wang, L. H., (2008). Adsorption of chromium (III) ion from aqueous solution using rice hull ash. Journal of the Chinese Institute of Chemical Engineers, 39 (4), 367-373.

[11]. R.K. Tiwary, S.K. Ghosh, D.C. Rupainwar, Y.C. Sharma, (1993) Managing aqueous solutions rich in Mn(II): an inexpensive technique, Colloids Surf. 70 131-137.

[12]. G. McKay, (1982) Adsorption of dyestuffs from aqueous solutions with activated carbon. Part I. Equilibrium and batch contact time studies, J. Chem. Technol. Biotechnol. 32 759-772. [13] G. McKay, A.G. Sweeny, (1980) Principles of dye removal from textile effluents, Water Air Soil Pollut. 14 3-11.

[13]. Srivastava, V.C, Mall,I., Mishra I.M., (2006) Equilibrium modeling of single and binary adsorption of cadmium and nickel onto bagasse fly ash. Chem. Eng. J. 117, 79-91

[14]. APHA, AWWA, WPCF, 1998 Standard Methods for Examination of Water and Wastewater, 20th ed., APHA, AWWA, WPCF, New York, 